\title{
Race disparities in mortality by breast cancer from 2000 to 2017 in São Paulo, Brazil: a population-based retrospective study
}

\author{
Ana Cláudia Marcelino, Bruno Gozzi, Cássio Cardoso-Filho, Helymar Machado, Luiz Carlos Zeferino and \\ Diama Bhadra Vale* (1)
}

\begin{abstract}
Background: In Brazil, inequalities in access may interfere with cancer care. This study aimed to evaluate the influence of race on breast cancer mortality in the state of São Paulo, from 2000 to 2017, contextualizing with other causes of death.

Methods: A population-based retrospective study using mortality rates, age and race as variables. Information on deaths was collected from the Ministry of Health Information System. Only white and black categories were used. Mortality rates were age-adjusted by the standard method. For statistical analysis, linear regression was carried out.

Results: There were 60,940 deaths registered as breast cancer deaths, 46,365 in white and 10,588 in black women. The mortality rates for 100,000 women in 2017 were 16.46 in white and 9.57 in black women, a trend to reduction in white $(p=0.002)$, and to increase in black women $(p=0.010)$. This effect was more significant for white women $(p<0.001)$. The trend to reduction was consistent in all age groups in white women, and the trend to increase was observed only in the 40-49 years group in black women. For 'all-cancer causes', the trend was to a reduction in white $(p=0.031)$ and to increase in black women $(p<0.001)$. For 'ill-defined causes' and 'external causes', the trend was to reduce both races $(p<0.001)$.
\end{abstract}

Conclusion: The declared race influenced mortality rates due to breast cancer in São Paulo. The divergences observed between white and black women also were evident in all cancer causes of death, which may indicate inequities in access to highly complex health care in our setting.

Keywords: Breast neoplasms, Mortality, Race/ethnicity, Racial disparities, Black women, Healthcare disparities

\section{Background}

Breast cancer is the main neoplasm that affects women in Brazil and worldwide, representing about 56 new cases and 13 deaths per 100,000 Brazilian women annually $[1,2]$. It is a relevant public health problem due to the number of lives affected, the impact on potentials

\footnotetext{
* Correspondence: dvale@unicamp.br

Obstetrics and Gynecology Department, State University of Campinas, Rua Alexander Fleming 101, Campinas, SP CEP 13083-881, Brazil
}

life-years lost, and the impact of the diagnosis and treatment on the health system. The incidence of breast cancer is increasing worldwide [3]. This increase is justified by the socioeconomic improvements, causing changes in women's habits, increase exposure to risk factors, such as postmenopausal hormonal therapies and obesity, and the widespread use of mammography detecting indolent cancers [3-5].

(c) The Author(s). 2021 Open Access This article is licensed under a Creative Commons Attribution 4.0 International License, which permits use, sharing, adaptation, distribution and reproduction in any medium or format, as long as you give appropriate credit to the original author(s) and the source, provide a link to the Creative Commons licence, and indicate if changes were made. The images or other third party material in this article are included in the article's Creative Commons licence, unless indicated otherwise in a credit line to the material. If material is not included in the article's Creative Commons licence and your intended use is not permitted by statutory regulation or exceeds the permitted use, you will need to obtain permission directly from the copyright holder. To view a copy of this licence, visit http://creativecommons.org/licenses/by/4.0/ The Creative Commons Public Domain Dedication waiver (http://creativecommons.org/publicdomain/zero/1.0/) applies to the data made available in this article, unless otherwise stated in a credit line to the data. 
In recent years, breast cancer mortality rates have decreased in high-income countries, increasing in low and middle-income countries [3, 6, 7]. Mortality from breast cancer is strongly influenced by stage and treatment [8]. The stage at diagnosis is influenced by women's access and adherence to early diagnosis programs. When systematically applied to the target population, mammography can reduce mortality from breast cancer [9].

In South America and the Caribbean, the ratio between mortality and incidence is more significant than observed in Europe and North America [6]. In Latin America, 41\% of women are diagnosed in stages III and IV, increasing incidence and mortality [10]. In Brazil, a country with significant regional inequalities, between 1980 and 2009 there was a trend to reduce mortality rates in the economically favoured Southeast region and to increase rates in the most impoverished Northeast region [11]. From 2001 to 2011, the Human Development Index significantly influenced a variation in mortality rates among Brazillian states [12]. Socioeconomic differences may explain those pieces of evidence.

Blacks and browns correspond to 55\% of the Brazilian population and represent the most economically disadvantaged strata [13]. In addition to social marginalization, this group also faces structural racism that can hamper access to health services and compromise care quality. This population has a higher degree of illiteracy, lower income, uses health services less and is more dependent on the public health system [14]. They also have lower life expectancy and mortality rates due to external causes, drug use and homicides [14].

Mortality rates due to breast cancer increased in black and brown women in Brazil aged 50 or more between 2000 and 2010 [15]. A regional study from 2003 to 2005 found that black women with breast cancer were diagnosed at more advanced stages and had shorter survival than white women in the same stage of diagnosis: specific 10-year survival of $70 \%$ for white and 44\% for black [16]. One hypothesis for the worst rates observed is that there could be variations in other causes of deaths, as improvements in the quality of registry in death certificates or decreases in other significant causes in the vulnerable population, such as "external" or violent causes.

To evaluate the influence of race on breast cancer, this work aims to demonstrate the evolution of mortality rates in São Paulo's state as a function of race from 2000 to 2017. We also sought to contextualize breast cancer deaths with other causes of death. Age groups were also analyzed to identify where the differences are more significant. Finally, it is hoped that this study may support the planning of specific public policies for cancer control and the global health of black women.

\section{Methods}

This is a population-based retrospective study using aggregated data on deaths from breast cancer among women living in the State of São Paulo, Southeast region of Brazil, whose death occurred between 2000 and 2017. Population data were obtained from the Brazilian Institute of Geography and Statistics (IBGE) [13]. The available variables age and race were analyzed. São Paulo's population was stable in the period, not prone to movements fluxes.

Information on deaths was collected from the Ministry of Health through the Mortality Information System (MIS) [17]. In Brazil, death certificates are compulsory, and physicians fill forms. Health departments of each municipality collect the information and record it periodically in the online national registry system, using the 10th International Classification of Diseases (ICD-10) for registration. Completeness is high. In addition to extracting "breast cancer" data (ICD-10 C50), it was decided to extract data on other mortality categories to assist in the analysis of the hypothesis: "cancer" (filter ICD-10 C00-C97), "external causes" (filter ICD-10 S00T99, V00-W99, Y00-Y99), "ill-defined causes” (filter "illdefined causes"). Also, age groups were analysed to qualify the analysis.

The MIS provides filters for age and race. For the denominator in the race, were used the proportions of the race categories by age-group of the female population in the São Paulo state, according to the IBGE's National Household Sample Survey (PNAD) [13]. The PNAD is a qualified census that permanently researches general characteristics of the population, education, work, income and housing, having the household as its research unit. The PNAD interviewers use the self-declared race for registration. When PNAD race data were not available (years 2000, 2010 and 2017), a projection was made by time trends. The IBGE and MIS categorize race into five classes: white, black, brown, yellow and indigenous. According to the proportion of the total population, the "ignored" race data were redistributed among the five categories. In Brazil, blacks and browns have the same African origin, brown indicating miscegenation of black with white people (European colones or immigrants). In this study we included only the white and black/brown categories (from now on grouped as "black"). There is a tendency to combine them as a single category by those who promtes racial debates, since both groups show similar socioeconomic indications of discrimination.

Deaths in children and women under 20 were discarded due to the high chance of corresponding to errors, and those "ignored" were redistributed by age groups $(0.02 \%)$. It was also redistributed those "ignored" race $(4.33 \%)$. The crude rates were calculated by the quotient between the total number of deaths and the 
population at risk for every 100,000 women. The adjusted rates per year were calculated considering the standard population of the World Health Organization of 2000 [18]. Then, the information on deaths by race versus the population's proportion was crossed to calculate the crude mortality rates by race and then ageadjusted rates.

For statistical analysis of the difference in rates by race and age was used linear regression analysis, with a significance level of $5 \%$. Three regression coefficients were used: B1, B2 and B3. B1 the increase or decrease over the years (the slope or year effect); B2 the difference in level between one series and another (the race effect); and B3 the difference between the slopes of the different series (the race vs year interaction term).

This study is part of the research project funded by FAPESP (2017/21908-1) and was approved by the Unicamp Research and Ethics Committee, registered at 'Plataforma Brasil' under the number CAAE 89399018.2.0000.5404. The Committee waived the need for the consent form due to the retrospective nature of the study and by the aggregated mode of data used.

\section{Results}

In the State of São Paulo, from 2000 to 2017, there were 60,940 deaths registered as breast cancer deaths, 46,365 in white and 10,588 in black women. The figures of the adjusted mortality rates by years, race and age groups, are displayed in Table 1 . Figure 1 shows the ageadjusted mortality rates over the years according to race. The rates for every 100,000 women varied from 19.1 in 2005 to 16.0 in 2014 in white (decrease of $16.2 \%$ ) and from 7.0 in 2006 to 9.6 in 2017 in black (increase of $37.1 \%)$. Over the years it was observed a significant trend to reduction in white women mortality rates $[\mathrm{B} 1=$ $(-) 0.10 ; p=0.002]$, and a significant trend to increase in black women mortality rates $[\mathrm{B} 1=(+) 0.07 ; p=0.010]$. This effect was more significant for white than for black women [white women with a greater inclination to fall: B3 $=(-) 0.18 ; p<0.001]$.

The evaluation of variations in rates according to agegroups by race can be seen in Fig. 2. For women aged $40-49$ years, mortality tended to decrease in white and to increase in black women $[\mathrm{B} 1=(-) 0.01 ; p=0.032$ and $\mathrm{B} 1=(+) 0.02 ; p=0.018$, respectively]. For the age-groups $50-59$ years, $60-69$ years and $70-79$ years, the trend observed in white women was to a reduction in mortality in all age-groups $[\mathrm{B} 1=(-) 0.05 ; p<0.001, \mathrm{~B} 1=(-) 0.02$; $p=0.012$ and $\mathrm{B} 1=(-) 0.02 ; p=0.004$, respectively]. In black women, there was no significant variation for these age-groups $[\mathrm{B} 1=(+) 0.02 ; p=0.066, \mathrm{~B} 1=(+) 0.01 ; p=$ 0.214 and $\mathrm{B} 1=(+) 0.01 ; p=0.435$, respectively].

Table 1 Women breast cancer adjusted mortality rates in São Paulo, Brazil, by race and age-groups, from 2000 to 2017

\begin{tabular}{|c|c|c|c|c|c|c|c|c|c|c|}
\hline \multirow[t]{2}{*}{ Years } & \multicolumn{2}{|l|}{40 to 49 years } & \multicolumn{2}{|l|}{50 to 59 years } & \multicolumn{2}{|c|}{60 to 69 years } & \multicolumn{2}{|l|}{70 to 79 years } & \multicolumn{2}{|l|}{ Total } \\
\hline & White & Black & White & Black & White & Black & White & Black & White & Black \\
\hline 2000 & 2.6 & 1.7 & 3.9 & 1.9 & 3.9 & 1.7 & 3.5 & 1.0 & 17.1 & 7.4 \\
\hline 2001 & 2.7 & 1.7 & 4.2 & 2.4 & 4.3 & 1.6 & 3.6 & 1.0 & 18.1 & 7.9 \\
\hline 2002 & 2.6 & 1.4 & 4.6 & 2.3 & 4.4 & 2.0 & 3.2 & 0.9 & 18.4 & 7.9 \\
\hline 2003 & 2.7 & 1.7 & 4.2 & 2.3 & 4.0 & 1.6 & 3.4 & 1.0 & 17.8 & 8.3 \\
\hline 2004 & 2.7 & 1.8 & 4.2 & 2.3 & 4.3 & 1.7 & 3.3 & 1.4 & 17.9 & 8.6 \\
\hline 2005 & 2.8 & 1.9 & 4.7 & 2.0 & 4.4 & 2.1 & 3.5 & 1.2 & 19.1 & 8.2 \\
\hline 2006 & 2.4 & 1.4 & 3.7 & 2.1 & 4.1 & 1.6 & 3.5 & 0.8 & 16.8 & 7.0 \\
\hline 2007 & 2.4 & 1.5 & 3.8 & 2.1 & 3.8 & 1.6 & 3.2 & 1.5 & 16.7 & 8.0 \\
\hline 2008 & 2.7 & 1.6 & 4.0 & 1.9 & 4.0 & 1.6 & 3.3 & 1.2 & 17.6 & 7.4 \\
\hline 2009 & 2.5 & 1.5 & 3.9 & 2.1 & 3.9 & 1.5 & 3.1 & 1.1 & 16.9 & 7.6 \\
\hline 2010 & 2.4 & 1.6 & 3.9 & 2.4 & 4.0 & 1.7 & 3.2 & 1.3 & 16.7 & 8.4 \\
\hline 2011 & 2.5 & 1.7 & 3.8 & 2.2 & 4.1 & 1.7 & 3.2 & 0.8 & 17.2 & 7.8 \\
\hline 2012 & 2.4 & 1.8 & 3.8 & 2.2 & 3.9 & 1.6 & 2.9 & 1.1 & 16.3 & 8.2 \\
\hline 2013 & 2.4 & 1.7 & 3.7 & 2.3 & 3.8 & 1.7 & 3.4 & 1.1 & 16.5 & 8.1 \\
\hline 2014 & 2.5 & 2.1 & 3.6 & 2.4 & 3.7 & 2.0 & 3.0 & 1.2 & 16.0 & 9.3 \\
\hline 2015 & 2.4 & 1.8 & 3.7 & 2.4 & 3.8 & 1.7 & 3.3 & 0.9 & 16.8 & 8.4 \\
\hline 2016 & 2.7 & 2.1 & 3.7 & 2.2 & 3.9 & 1.9 & 3.3 & 1.2 & 17.0 & 9.1 \\
\hline 2017 & 2.4 & 1.8 & 3.6 & 2.6 & 4.0 & 2.1 & 3.0 & 1.4 & 16.5 & 9.6 \\
\hline B1 (p) & $-0.01(0.032)$ & $0.02(0.018)$ & $-0.05(<0.001)$ & $0.02(0.066)$ & $0.02(0.012)$ & $0.01(0.214)$ & $-0.02(0.004)$ & $0.01(0.435)$ & $-0.10(0.002)$ & $0.07(0.010)$ \\
\hline$B 2(p)$ & $1.14(<0.001)$ & & $2.24(<0.001)$ & & $2.57(<0.001)$ & & $2.42(<0.001)$ & & $10.50(<0.001)$ & \\
\hline B3 (p) & $-0.03(0.001)$ & & $-0.06(<0.001)$ & & $-0.03(0.006)$ & & $-0.03(0.011)$ & & $-0.18(<0.001)$ & \\
\hline
\end{tabular}

p p-value; (-) indicates a tendency towards a reduction in rates. Statistics by linear regression: B1, the slope or year effect; B2, the race effect; B3, the race vs year interaction term 


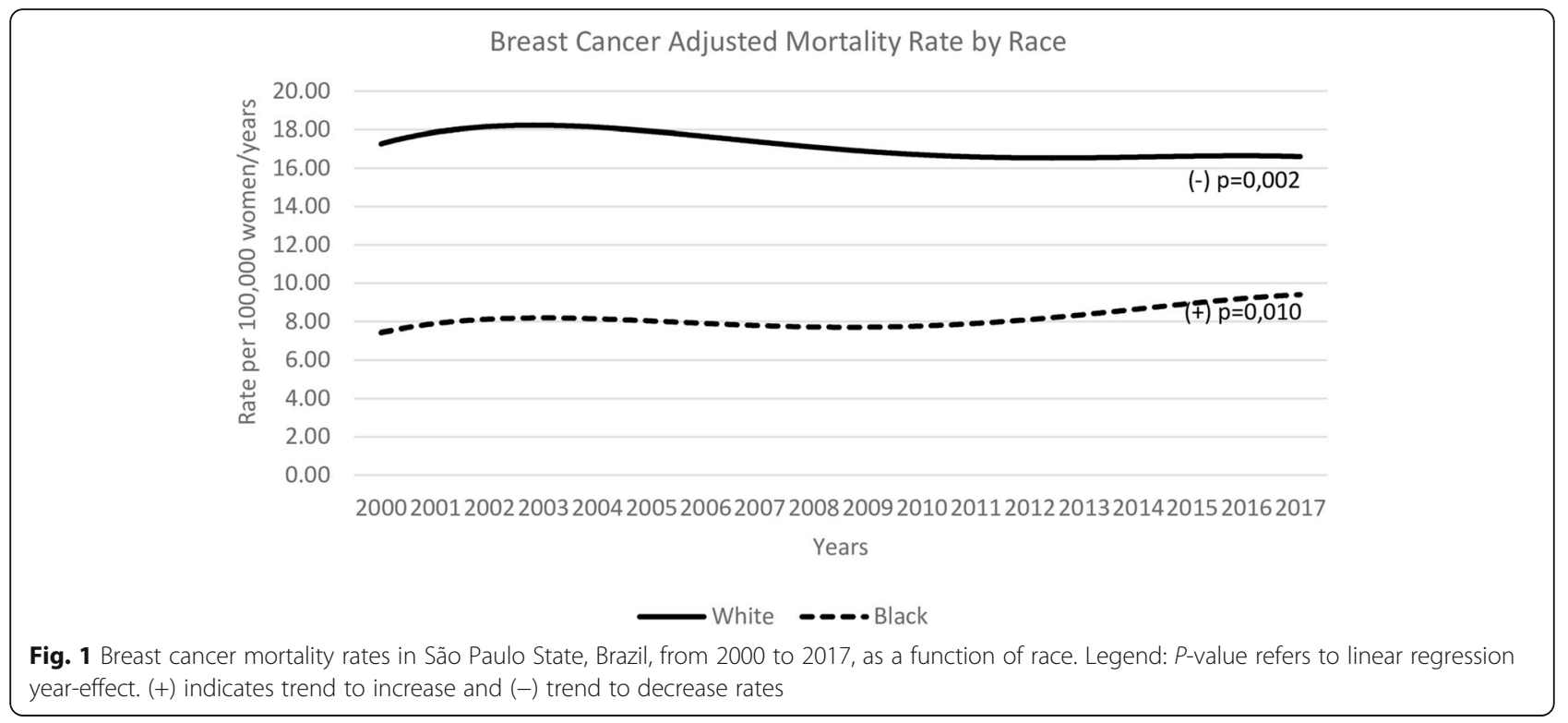

The figures of the adjusted mortality rates by years and the causes of death are displayed in Table 2. The analysis of other causes of death according to race is presented in Fig. 3. In the category 'all-cancer causes', the trend was to a reduction in mortality rates in white women $[\mathrm{B} 1=(-) 0.34 ; p=0.031]$ and an increase in black women $[\mathrm{B} 1=(+) 0.42 ; p<0.001]$. This effect was more significant for the reduction among white women $[\mathrm{B} 3=$ $(-) 0.75 ; p<0.001]$. For "ill-defined causes", the trend was in a decrease among white and black women $[\mathrm{B} 1=$ $(-) 1.06 ; p<0.001$ and $\mathrm{B} 1=(-) 0.75 ; p<0.001]$, respectively. For 'external causes', there was a reduction over the years for both races $[\mathrm{B} 1=(-) 0.26 ; P<0.001$ in white and $\mathrm{B} 1=(-) 0.43 ; P<0.001$ black women], with an explicit difference on the races $(\mathrm{B} 2=6.84 ; P<0.001)$.

\section{Discussion}

In this study of assessment of breast cancer mortality rates from 2000 to 2017 in women from São Paulo, Brazil, it was observed that, while in white women the rates tend to a reduction, in black women the rates tend to increase. The same trends were observed in cancer mortality rates in general. The woman's age in the year of death did not influence this result, as the death records' qualification and the reduction in deaths due to external or violent causes.

The reduction in breast cancer mortality is the result of improved access to early diagnosis and timely treatment. The therapeutic evolution, especially the development of new drugs and specific therapies, is considered the main factor that has impacted breast cancer mortality in recent decades $[8,19]$. Trastuzumab, for example, is available in the universal health care system since
2013 in São Paulo state, so women carrying the HER2/ neu protein would have a better prognosis [19].

However, inequity in access to therapeutic modalities can influence population rates in different ways. The trend observed in the reduction of mortality in white women as opposed to the increase in rates in black women indicates the evident influence of race on this issue in the Brazilian population.

The incidence rates of breast cancer are increasing in Brazil and worldwide [3]. Therefore, without adequate intervention, mortality rates are also expected to increase. The increase in mortality rates among black women may reflect delay in diagnosis, difficulty in accessing highly complex services for treatment or biological variations. In North American women, rates in black women are $21 \%$ lower for the hormonal receptor (HR) and HER2 positive, 29\% higher in HR negative and HER2 positive, and 93\% higher for triple-negative subtypes [20]. This data may justify the rough differences observed among race, but not the opposite trends observed in the study.

The increase in cancer mortality rates in general observed in this study suggests that access to treatment should be a significant factor influencing these results. Delays in surgical treatment due to race are reported in the USA [21]. Also, racial minorities are more likely to receive more non-standardized treatments (out of standard protocols), such as less indication for surgical treatment, fewer sentinel lymph node biopsies and reconstructions, and less access to adjuvant treatment [21-24]. There is a greater chance of delaying its onset regarding chemotherapy and hormone therapy, which can lead to significant differences in survival $[21,25]$. In 
Breast Cancer Mortality Rates in White Women by Age

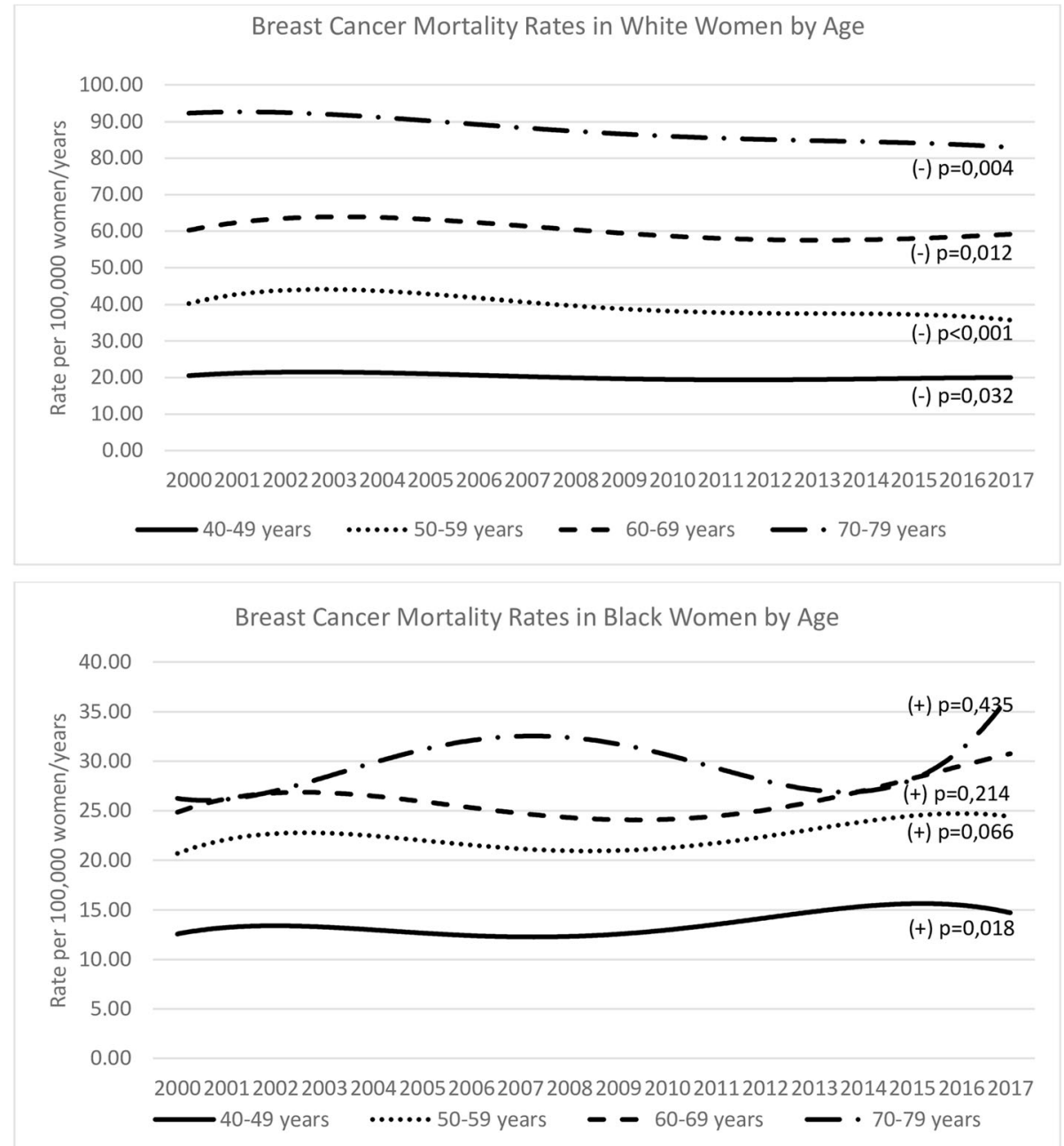

Fig. 2 Breast cancer mortality rates in São Paulo State, Brazil, from 2000 to 2017, by age-groups, as a function of race. Legend: P-value refers to linear regression year-effect. $(+)$ indicates trend to increase and $(-)$ trend to decrease rates

Brazil, more significant delays have been reported in populations with lower income, less education and nonwhite ethnic groups [26].

A possible explanation for these evidence is that socioeconomic variables are influencing the race factor. However, it is necessary to consider a potential implicit bias in the health professional behaviour when a difference in the preference for a given social group would negatively impact communication, clinical investigation and decision in the treatment of vulnerable patients [22]. In Brazil, an assessment of satisfaction with health care and hospitalization observed $12.2 \%$ of non-satisfied white patients and $17.4 \%$ among blacks and browns patients [14]. The probability of a black or brown person looking for a health service and not being seen is twice as high as a white person [14].

In general, international literature does not support the hypothesis of a biological plausibility that would justify these observed differences. A population-based study in the USA showed that the black population is twice as susceptible to death as the white population in tumours that express hormone receptors in the first 2 years after diagnosis, with no difference between the triple-negative types. The disparities persisted after accounting for factors as stage, tumour characteristics, and body mass index. However, black/white disparities persisted after accounting for those factors. Authors suggest that incomplete or delayed receipt of treatment may have influenced the results [27]. Another study points out that despite hormonal subtype, socioeconomic status or access to health services, racial disparities in diagnosis, treatment and survival still persist [23].

The incidence of hormone receptor-negative tumours is higher in black than in white women [23, 28, 29]. Certain genetic factors may be associated with this fact, such as more frequent mutations in BRCA and others. However, the real functional impact of these on the incidence 
Table 2 Adjusted women mortality rates in São Paulo, Brazil, by race and causes of death, from 2000 to 2017

\begin{tabular}{|c|c|c|c|c|c|c|c|c|}
\hline \multirow[t]{2}{*}{ Year } & \multicolumn{2}{|l|}{ Breast Cancer } & \multicolumn{2}{|c|}{ All cancer causes } & \multicolumn{2}{|c|}{ III-defined causes } & \multicolumn{2}{|l|}{ External causes } \\
\hline & White & Black & White & Black & White & Black & White & Black \\
\hline 2000 & 17.1 & 7.4 & 100.4 & 47.3 & 37.9 & 23.1 & 25.3 & 20.8 \\
\hline 2001 & 18.1 & 7.9 & 104.0 & 49.9 & 40.1 & 23.4 & 25.9 & 18.9 \\
\hline 2002 & 18.4 & 7.9 & 104.8 & 47.7 & 38.9 & 22.5 & 25.3 & 20.1 \\
\hline 2003 & 17.8 & 8.3 & 108.3 & 47.2 & 37.9 & 22.7 & 24.8 & 18.7 \\
\hline 2004 & 17.9 & 8.6 & 106.6 & 50.2 & 38.0 & 21.4 & 26.3 & 17.4 \\
\hline 2005 & 19.1 & 8.2 & 111.3 & 47.2 & 35.7 & 18.3 & 26.5 & 17.4 \\
\hline 2006 & 16.8 & 7.0 & 101.7 & 45.4 & 35.0 & 18.8 & 22.8 & 14.3 \\
\hline 2007 & 16.7 & 8.0 & 103.3 & 48.4 & 34.7 & 17.6 & 22.4 & 13.0 \\
\hline 2008 & 17.6 & 7.4 & 107.7 & 45.0 & 33.5 & 16.6 & 24.2 & 13.0 \\
\hline 2009 & 16.9 & 7.6 & 105.7 & 46.6 & 33.4 & 16.7 & 23.5 & 14.0 \\
\hline 2010 & 16.7 & 8.4 & 101.0 & 50.0 & 32.1 & 16.1 & 22.4 & 14.8 \\
\hline 2011 & 17.2 & 7.8 & 103.7 & 49.5 & 32.1 & 14.2 & 23.6 & 13.6 \\
\hline 2012 & 16.3 & 8.2 & 100.7 & 50.7 & 27.5 & 14.1 & 23.7 & 14.0 \\
\hline 2013 & 16.5 & 8.1 & 99.2 & 50.9 & 25.5 & 12.9 & 22.2 & 13.7 \\
\hline 2014 & 16.0 & 9.2 & 97.7 & 54.7 & 24.6 & 13.3 & 22.3 & 15.0 \\
\hline 2015 & 16.8 & 8.4 & 100.5 & 54.1 & 24.0 & 11.9 & 21.8 & 13.6 \\
\hline 2016 & 17.0 & 9.1 & 101.6 & 52.7 & 25,0 & 12.3 & 21.9 & 12.9 \\
\hline 2017 & 16.5 & 9.6 & 101.6 & 55.5 & 21.9 & 12.0 & 21.4 & 12.2 \\
\hline B1 (p) & $-0.10(0.002)$ & $0.07(0.010)$ & $-0.34(0.031)$ & $0.42(<0.001)$ & $-1.06(<0.001)$ & $-0.75(<0.001)$ & $-0.26(<0.001)$ & $-0.43(<0.001)$ \\
\hline$B 2(p)$ & $10.50(<0.001)$ & & $60.10(<0.001)$ & & $17.65(<0.001)$ & & $6.84(<0.001)$ & \\
\hline B3 (p) & $-0.18(<0.001)$ & & $-0.75(<0.001)$ & & $-0.31(<0.001)$ & & $0.17(0.046)$ & \\
\hline
\end{tabular}

$p$ p-value; (-) indicates a tendency towards a reduction in rates. Statistics by linear regression: B1, the slope or year effect; B2, the race effect; B3, the race vs year interaction term

and progression of triple-negative cancers in this population is still unknown [24]. In the specific case of tumours with negative hormone receptors, it is known that the delay in diagnosis and referral can compromise the effectiveness of the treatment [23].

In this study, data on stage and molecular subtypes were not available. It is known that more aggressive tumours tend to affect younger populations [30, 31]. In women aged 40 to 49 , mortality decreased significantly among white women and increased significantly among black women. It is not possible to determine whether tumours in black women were more aggressive than those in white women. One explanation to have not observed increased trends in older women is the low number of cases at the sub-groups. Still, this data also reinforces the hypothesis of less access to treatment faced by black women. Survival studies can elucidate this issue.

The hypothesis that an improvement may have influenced mortality rates in the quality of filling out death certificates among black women in the period was investigated. The analysis of mortality rates due to ill-defined causes revealed that the tendency towards reduction was observed for both white and black women, with a more critical fall among white women, which could have influenced the results in an inverse way to the hypothesis made. Another interesting fact is that in the period, there was a significant reduction in mortality from external causes in the population in general, more significant among white women, which should not have influenced the results either.

This is a population-based study in a region that concentrates about $1 / 5$ of the Brazillian population, representing other large urban centres in middle-income countries. São Paulo state focuses most of the highquality care in Brazil, public and private, so the results found in this study must be highlighted when extrapolating to other regions where health care is not so developed. However, it is also important to note that the data from the death registry information system in the State of São Paulo is considered the best in the country. In this way, we believe that this is the best information obtained for the analyses to be carried out.

The study's main limitations are the lack of data on the stage and molecular subtypes of breast cancers. Also, we did not have data in incidence to interpret the study results better. However, we believe that access to treatment, which would mainly affect mortality, is parallel to access to diagnosis, which would mainly affect incidence. In this sense, once treatment care would be improved, 


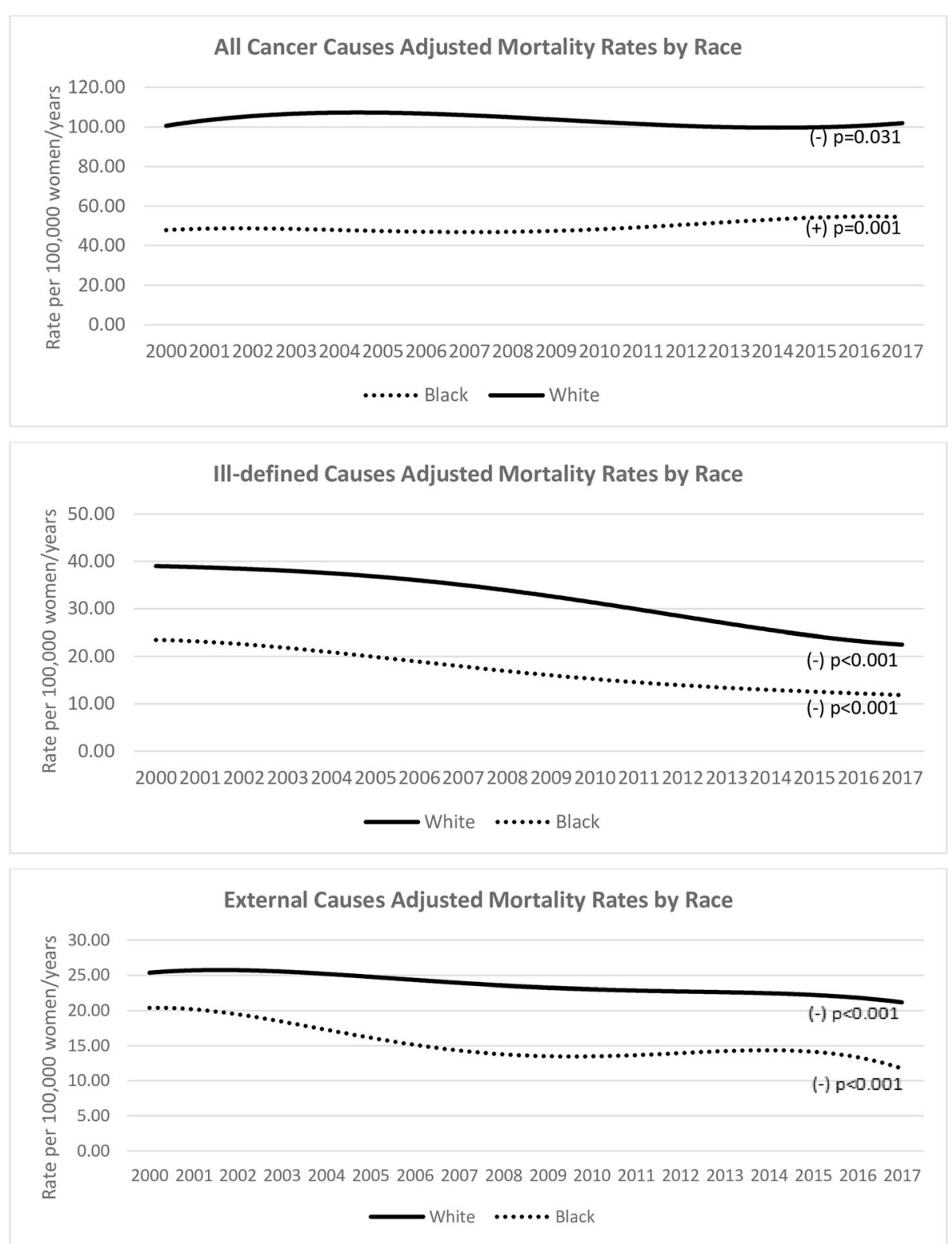

Fig. 3 Breast cancer mortality rates in São Paulo State, Brazil, from 2000 to 2017, by causes of death and race. Legend: P-value refers to year-effect linear regression. $(+)$ indicates trend to increase and $(-)$ trend to decrease rates

diagnosis also would be better. No significant cultural behaviour change was observed in habits in the period to influence risk factors. We believe that future survival analyzes from population-based cancer registries can support the evidence generated in this study.

\section{Conclusion}

The declared race influenced mortality rates due to breast cancer in São Paulo. The divergences observed between white and black women also were evident in all cancer causes of death, which may indicate inequities in access to highly complex health care in our setting.

\section{Abbreviations}

B1: The slope or year effect; B2: The difference in level between one series and another (the race effect); B3: The difference between the slopes of the different series (the race vs year interaction term).; IBGE: Brazilian Institute of Geography and Statistics; ICD-10: 10th International Classification of Diseases; HR: Hormonal Receptor; MIS: Mortality Information System; PNAD: National Household Sample Survey

\section{Acknowledgements}

Not applicable.

\section{Authors' contributions}

ACM, BG and DBV conceived and designed the work. BG acquired data and HM analyzed it. CCF and LCZ made substantial contribution interpreting data. ACM and DBV drafted the work and revised it critically for important 
intellectual content. All authors approved the version to be published and agree to be accountable for all aspects of the work.

\section{Funding}

This study was performed during the tenure of the research funding of the "Fundação de Amparo à Pesquisa do Estado de São Paulo (FAPESP)", registered under the number 2017/21908-1. The study sponsors had no involvement in the study other than funding.

\section{Availability of data and materials}

The datasets analyzed during the current study are available in the SIM repository: http://tabnet.datasus.gov.br/cgi/deftohtm.exe?sim/cnv/obt10sp.def and the IBGE repository: https://www.ibge.gov.br/estatisticas/sociais/populacao. html. The datasets generated during and/or analyzed during the current study are available from the corresponding author on reasonable request.

\section{Declarations}

\section{Ethics approval and consent to participate}

The Unicamp Research and Ethics Committee approved this study under the number CAAE 89399018.2.0000.5404. The Committee waived the need for the consent form due to the retrospective nature of the study and by the aggregated mode of data used. All methods were performed in accordance with the relevant guidelines and regulations.

\section{Consent for publication}

Not applicable.

\section{Competing interests}

The authors declare that they have no competing interests.

Received: 13 April 2021 Accepted: 18 August 2021

Published online: 07 September 2021

\section{References}

1. Bray F, Ferlay J, Soerjomataram I, Siegel RL, Torre LA, Jemal A. Global cancer statistics 2018: GLOBOCAN estimates of incidence and mortality worldwide for 36 cancers in 185 countries. CA Cancer J Clin. 2018;68(6):394-424. https://doi.org/10.3322/caac.21492.

2. Brasil - Instituto Nacional do Câncer. Estimativas de Câncer 2020: INCA Instituto Nacional de Câncer; 2018. https://www.inca.gov.br/numeros-de-ca ncer. Accessed 8 Feb 2020

3. DeSantis CE, Bray F, Ferlay J, Lortet-Tieulent J, Anderson BO, Jemal A. International variation in female breast Cancer incidence and mortality rates. Cancer Epidemiol Biomark Prev. 2015;24(10):1495-506. https://doi.org/10.11 58/1055-9965.EPI-15-0535.

4. Jemal A, Ward E, Thun MJ. Recent trends in breast cancer incidence rates by age and tumor characteristics among U.S. women. Breast Cancer Res. 2007:9:R28.

5. Arslan AA, Formenti SC. Mammography in developing countries: the risks associated with globalizing the experiences of the Western world. Nat Clin Pract Oncol. 2009;6(3):136-7. https://doi.org/10.1038/ncponc1282.

6. Bray F, Jemal A, Grey N, Ferlay J, Forman D. Global cancer transitions according to the human development index (2008-2030): a populationbased study. Lancet Oncol. 2012;13(8):790-801. https://doi.org/10.1016/S14 70-2045(12)70211-5.

7. Di Sibio A, Abriata G, Forman D, Sierra MS. Female breast cancer in central and South America. Cancer Epidemiol. 2016;44(Suppl 1):S110-20. https://doi. org/10.1016/j.canep.2016.08.010.

8. Guo F, Kuo Y-F, Shih YCT, Giordano SH, Berenson AB. Trends in breast cancer mortality by stage at diagnosis among young women in the United States. Cancer. 2018;124(17):3500-9. https://doi.org/10.1002/cncr.31638.

9. Lauby-Secretan B, Scoccianti C, Loomis D, Benbrahim-Tallaa L, Bouvard V, Bianchini F, et al. Breast-Cancer screening — viewpoint of the IARC working group. N Engl J Med. 2015:372(24):2353-8. https://doi.org/10.1056/NEJMsr1504363.

10. de Lemos LLP, Carvalho de Souza M, Pena Moreira D, Ribeiro Fernandes Almeida PH, Godman B, Verguet S, et al. Stage at diagnosis and stagespecific survival of breast cancer in Latin America and the Caribbean: A systematic review and meta-analysis. PLoS One. 2019;14:e0224012.

11. Freitas-Junior R, Gonzaga CMR, Freitas NMA, Martins E, Dardes R. Disparities in female breast cancer mortality rates in Brazil between 1980 and 2009. Clinics. 2012;67:731-7.
12. Gonzaga CMR, Freitas-Junior R, Curado M-P, Sousa A-LL, Souza-Neto J-A, Souza MR. Temporal trends in female breast cancer mortality in Brazil and correlations with social inequalities: ecological time-series study. BMC Public Health. 2015;15(1):96. https://doi.org/10.1186/s12889-015-1445-7.

13. Instituto Brasileiro de Geografia e Estatísitca. População | IBGE. https://www. ibge.gov.br/estatisticas/sociais/populacao.html. Accessed 14 Jan 2021.

14. Paixão M, Rosseto I, Montovanele F, Carvano L. Relatório Anual das Desigualdades Raciais no Brasil; 2009-2010; 2010.

15. Soares LR, Gonzaga CMR, Branquinho LW, Sousa A-LL, Souza MR, Freitas-Junior R. Female breast cancer mortality in Brazil according to color. Rev Bras Ginecol Obstet. 2015:37(8):388-92. https://doi.org/10.1590/S0100-720320150005319.

16. Nogueira MC, Guerra MR, Cintra JRD, Corrêa CSL, Fayer VA, Bustamante-Teixeira MT. Racial disparity in 10-year breast cancer survival: a mediation analysis using potential responses approach. Cad Saude Publica. 2018;34:e00211717.

17. Ministério da Saúde. Sistema de Informação de Mortalidade - TabNet http://tabnet.datasus.gov.br/cgi/deftohtm.exe?sim/cnv/obt10uf.def. Accessed 14 Jan 2021

18. Ahmad OB, Boschi-Pinto C, Lopez AD, Murray CJ, Lozano R, Inoue M, et al. Age standardization of rates: a new WHO standard. Geneva: World Health Organization; 2001. http://www.who.int/entity/healthinfo/paper31.pdf?ua=1. Accessed 28 May 2015

19. Paik S, Kim C, Wolmark N. HER2 Status and Benefit from Adjuvant Trastuzumab in Breast Cancer; 2009. https://doi.org/10.1056/NEJMc0801440.

20. Sung $H$, DeSantis $C$, Jemal A. Subtype-specific breast Cancer incidence rates in black versus White men in the United States. JNCI Cancer Spectrum. 2020:4(1). https://doi.org/10.1093/jncics/pkz091.

21. Reeder-Hayes KE, Anderson BO. Breast Cancer disparities at home and abroad: a review of the challenges and opportunities for system-level change. Clin Cancer Res. 2017;23(11):2655-64. https://doi.org/10.1158/10780432.CCR-16-2630.

22. de Jager E, Levine AA, Udyavar NR, Burstin HR, Bhulani N, Hoyt DB, et al, Disparities in surgical access: a systematic literature review, conceptual model, and evidence map. J Am Coll Surg. 2019;228(3):276-98. https://doi. org/10.1016/j.jamcollsurg.2018.12.028

23. Akinyemiju T, Sakhuja S, Vin-Raviv N. Racial and socio-economic disparities in breast cancer hospitalization outcomes by insurance status. Cancer Epidemiol. 2016:43:63-9. https://doi.org/10.1016/j.canep.2016.06.011.

24. Siddharth S, Sharma D. Racial disparity and triple-negative breast cancer in African-American women: a multifaceted affair between obesity, biology, and socioeconomic determinants. Cancers. 2018;10:514.

25. Green AK, Aviki EM, Matsoukas K, Patil S, Korenstein D, Blinder V. Racial disparities in chemotherapy administration for early-stage breast cancer: a systematic review and meta-analysis. Breast Cancer Res Treat. 2018;172(2): 247-63. https://doi.org/10.1007/s10549-018-4909-5.

26. Vieira RA, Formenton A, Bertolini SR. Breast cancer screening in Brazil. Barriers related to the health system. Rev Assoc Med Bras. 2017;63:466-74.

27. Warner ET, Tamimi RM, Hughes ME, Ottesen RA, Wong Y-N, Edge SB, et al Racial and ethnic differences in breast Cancer survival: mediating effect of tumor characteristics and sociodemographic and treatment factors. J Clin Oncol. 2015;33(20):2254-61. https://doi.org/10.1200/JCO.2014.57.1349.

28. Hung M-C, Ekwueme DU, Rim SH, White A. Racial/ethnicity disparities in invasive breast cancer among younger and older women: an analysis using multiple measures of population health. Cancer Epidemiol. 2016:45:112-8. https://doi.org/10.1016/j.canep.2016.10.013.

29. Yedjou CG, Sims JN, Miele L, Noubissi F, Lowe L, Fonseca DD, et al. Health and racial disparity in breast Cancer. Adv Exp Med Biol. 2019;1152:31-49. https://doi.org/10.1007/978-3-030-20301-6 3.

30. Yoshida M, Shimizu C, Fukutomi T, Tsuda H, Kinoshita T, Akashi-Tanaka S, et al. Prognostic factors in young Japanese women with breast cancer: prognostic value of age at diagnosis. Jpn J Clin Oncol. 2011;41(2):180-9. https://doi.org/10.1093/jjco/hyq191.

31. Liu P, Li X, Mittendorf EA, Li J, Du XL, He J, et al. Comparison of clinicopathologic features and survival in young American women aged 1839 years in different ethnic groups with breast cancer. Br J Cancer. 2013; 109(5):1302-9. https://doi.org/10.1038/bjc.2013.387.

\section{Publisher's Note}

Springer Nature remains neutral with regard to jurisdictional claims in published maps and institutional affiliations. 